\title{
Study and Application of the Networked Lab Management Model
}

\author{
Sainan Zhang \\ Department of Teaching Affairs Jilin Agricultural University, 130118, Changchun, China
}

Zhangsainan8304@126.com

Keywords: institutions of higher learning; labs; networked management

\begin{abstract}
This paper expounds the status quo of the lab management in institutions of higher learning and analyzes the existing problems and development problems. In view of the development trend of the networked lab management model in institutions of higher learning and targeted at the lab construction and management, allocation and scientific use of lab devices and experiment content, this paper puts forward the networked lab management model in line with the practical characteristics of institutions of higher learning based on the exposition of the construction of networked lab management system. The research findings of this paper can provide theoretical references for the innovation management models and promote the networked lab management in institutions of higher learning.
\end{abstract}

\section{Introduction}

With China's vigorous investment in institutions of higher learning and the dramatic expansion of the school running model caused by institutions of higher learning, the purchase and allocation of large quantities of advanced devices, the problems facing lab management has been more and more obvious. The old concepts and imperfect management mechanism cannot meet the requirements of the modern labs. The current lab management completely features artificial management, thus having brought about the following problems: 1) unable to quickly, completely and exactly gain the lab basic information, including lab construction status, schedule of all kinds of practical teaching and personnel management; 2) too complex task allocation process of lab technicians; 3) repeated entry of information, including experiment guidance, experiment planning, experiment report and original record and inconvenient information consulting; 4) tedious management formalities, including the consulting, maintenance and calibration of experiment instruments and devices, and issue and consulting of various standard texts; and 5) poor status of resources sharing since computers in different departments are used independently though all labs have been equipped with computers. The lab management status quo without the adoption of various modernized management means suggests that the necessity of introducing the networked lab management platform $^{[1]}$.

Concerning the above situation, this paper puts forward the networked lab management system in line with the practical needs of institutions of higher learning aiming at achieving computer assisted instruction teaching and networked and intelligent management. The active research and development of open networked lab management system can create a humane experiment environment, stimulate students' exploration spirit and scientific thinking, improve their practical and innovational ability and ensure the quality of experiment teaching. Besides, the employment of the lab management system can achieve the standard and informationalized management of labs, lab instruments and lab consumables in institutions of higher learning, significantly improve the management and service level of practical teaching, especially open and practical teaching, and provide data support for the decision-making of lab evaluation, lab construction and practical 
teaching quality.

\section{Construction of the networked lab management system}

\section{Introduction of the system's function modules}

Instruments, devices, consumables and teaching are essential to labs, so the function modules of the lab management system must include the management of the three aspects ${ }^{[2]}$. The system's function modules are shown in Fig.1.

$\diamond$ Lab management: Including announcement management, user management and data dictionary;

$\diamond$ Lab teaching management: Including the teaching plan, upload and approval of the teaching resources, document and students' data and statements, exam result management;

$\diamond$ Instrument and device management: Including the management related to the acquisition, storage, use, maintenance and consumption of experimental devices;

$\diamond$ Low-valued items and consumables' management: Including the management of the acquisition , storage, use, supplement and consumption of the low-valued items and consumables;

$\diamond$ Lab construction device purchase: Including the management of lab construction schedule and device purchase procedures;

$\diamond$ Evaluation of the lab and lab teaching: Including the users' evaluations statistics of lab management and teaching;

$\diamond$ Data and statements: Including the consulting of the statistics of the number of lab personnel, experiment records, work summaries, work plans, experiment templates, purchased reagents, devices and instruments, etc.

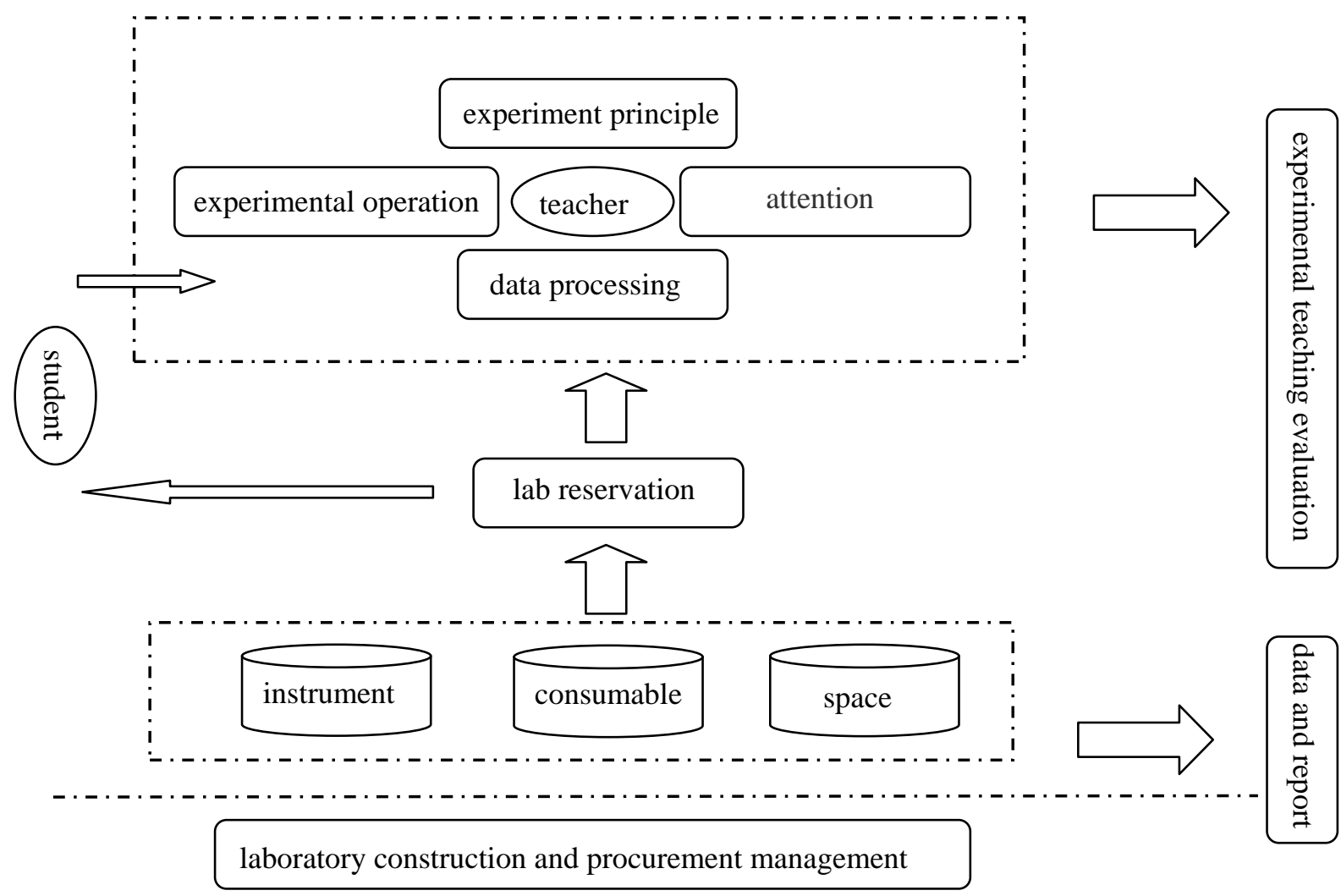

Fig1. The functional diagram of the laboratory management system

Besides, the function of lab reservation and knowledge that the students must be familiar with and review before doing the experiment, including experiment principles, process and data can be 
included in the lab teaching management modules. The whole system should closely integrate teachers, students and lab management personnel ${ }^{[3]}$.

\section{System's development mode and framework design}

The system adopts Java as the developing language, mysql developed by Oracle as the database and tomcat as the server publishing application. Besides, the core thread used by mysql is complete multiple thread, which supports multi-processor. Through a highly optimized class library, it achieves the SQL function library and becomes as fast as they are. Usually, after the consulting is initiated, there should be neither memory allocation, nor internal storage loopholes.

The system adopts B/S system framework, which can achieve a paperless and convenient office environment by allowing different personnel with different right permissions to visit and operate the shared database from different locations and different accesses, such as LAN, WAN, Internet/Intranet, etc. Besides, it gets rid of the regional limitation of $\mathrm{C} / \mathrm{S}$ framework and inconvenience of work. Moreover, in terms of security, B/S framework can achieve the separation of the system server and the data server, thus fundamentally protecting the system's data security. Therefore, compared with C/S, B/S greatly simplifies the client side ${ }^{[4]}$.

\section{Design of the system's database}

Name of the form: function_series list form (records the ID numbers and names of the function series);

Tab. 1 function series table

\begin{tabular}{lll}
\hline Field & Data Types & Explanation \\
\hline ID & INT & Functional Series ID number, Primary key \\
NAME & NVARCHAR(20) & Functional Series name \\
MEMO & NVARCHAR(20) & Remark \\
LAST_CHANGE_TIME & TIMESTAMP & Last modification time \\
\hline
\end{tabular}

Name of the form: function form (records the function ID, function name, request paths of corresponding functions, function type, etc.)

Tab. 2 function table

\begin{tabular}{lll}
\hline Field & Data Types & Explanation \\
\hline PF_ID & INT & Function ID number, Primary key \\
PF_NAME & NVARCHAR(20) & Function Name \\
PF_URL & NVARCHAR(50) & Corresponding to URL \\
PT_ID & INT & Function Type ID \\
MEMO & NVARCHAR(20) & Remark \\
LAST_CHANGE_TIME & TIMESTAMP & Last modification time \\
\hline
\end{tabular}

\section{System's application and effect}

\section{System's operation procedures}

Login authentication and permission distribution The system will verify information entered by the user. If what the user entered in is correct, the user's information will be saved in the users' session and relevant rights will be allocated to the user with a menu bar generated in the left side according to the right permission of the user.

Lab management. After the user logs in successfully, he/she can manage the lab information within his/her management scope. Before the visit, the user should firstly pass the permission validation, which is conducted through the permission validation interceptor.

The school-level administrators can only check the operations; the college-level administrators 
can newly establish, edit, delete files or conduct other operations of the first-level lab and the subsidiary lab; the first-level administrators can only newly establish, edit, delete files or conduct other operations of the subsidiary lab.

\section{Application effect}

The formation of a complete networked lab teaching management system can connect lab teaching content, purchase of experimental consumables, management of lab personnel, use and management of instruments and devices, which can contribute to coordinated management and real-time monitoring of the complete multi-thread and ensure the smooth progress of various experimental teaching activities. The management model is: administrators of various departments immediately enter various data into the networked management system before the teaching activity starts $\rightarrow$ administrators of the school departments immediate conduct periodical check, verification and analysis of the data $\rightarrow$ give the feedback of the periodical check result to the college $\rightarrow$ achieve complete monitoring of the teaching quality of one semester ${ }^{[5]}$.

The implementation of networked management model for lab teaching can provide a convenient and time-saving communication platform for the school's administration departments, teachers and students. They can visit and learn the personnel allocation, device and instrument allocation, experimental projects and scientific research projects at any time and any place. Different labs can exchange and coordinate with each other to share their resources so as to provide accurate data for the lab's administrators and departments in charge, and improve management efficiency and quality.

\section{Conclusions}

Thanks to Chinese government's efforts, the campus network in institutions of higher learning has been constantly developed and completed. Currently, as the functions of the network software development tools become more and more powerful, the establishment of a unified networked lab management platform in all institutions of higher learning is of vital significance to the lab management work in institutions of higher learning in the perspective of saving investments and improving functions.

\section{Acknowledgement}

This article is the phased achievement of the Twelfth Five-Year Program Suject of the 2014 Jilin Education Science "The Construction and Practice of the Curriculum System Expanding the Qualiti es of College Students'Practical Skills in Local Agricultural Universities".

\section{References}

[1] Li Jiannan, et al. The Status Quo and Management of Experiment Teaching Management in Institutions of Higher Learning[J]. Experiment Science and Technology, 2011 (2): 138-140.

[2] Guo Jian, et al. Reflections on the Evaluation System of the School-level Experiment Teaching Quality[J]. Experiment Science and Technology, 2010, 8 (4): 126-127.

[3] Jiang Fengbin. The Exploration and Study of Networked Computer-assisted Lab Management Model in Institutions of Higher Learning[J]. Science Mosaic, 2011 (1): 151-154.

[4] Chen Shan, Chen Runen, Luan Changping, et al. The Exploration and Practices of Networked Lab Management in Institutions of Higher Learning[J]. Journal of Hunan University of Science \& Technology, 2009 (8): 93-95.

[5] Hang Yiping. Reflections on the Evaluation of the Effectiveness of the Networked Lab Management in Institutions of Higher Learning[J]. Higher Education Sciences, 2009 (4): 90-92. 